\title{
Effect of fiber ratio on the impact behavior of polypropylene fiber reinforced samples
}

\author{
Mehmet Fatih Şahan ${ }^{1}$ (D), Fatih Ali Öncel ${ }^{2}$, İsmail Ünsal ${ }^{* 1}$ iD \\ ${ }^{1}$ Adlyaman University, Faculty of Engineering, Department of Civil Engineering, Adlyaman, Turkey \\ ${ }^{2}$ Adlyaman University, Graduate Education Institute, Department of Civil Engineering, Adlyaman, Turkey
}

\begin{abstract}
This study investigated the effect of fiber ratio on the impact behavior of polypropylene fiber reinforced concrete cube and beam samples. Plain concrete mixtures for control samples and polypropylene fiberreinforced concrete mixtures with fiber ratios of $\% 0.22, \% 0.44$, and $\% 0.66$ by volume were prepared. An instrumented drop-weight impact system was used for the dynamic tests. Static compression tests, threepoint bending tests, and impact tests were performed on beam samples (with the dimension of $100 \times 100 \times 500$ $\mathrm{mm}$ ). Static compression and impact tests were performed on cube samples (with the size of $100 \mathrm{~mm}$ ). It was observed that the fracture properties of polypropylene fiber reinforced concrete for both cube and beam samples were better than the control samples under impact. The crack width in the beams under the impact decreased with the increase in polypropylene fiber ratio. The cube and beam concrete samples reinforced with polypropylene fibers absorbed the impact energy better than the control samples.
\end{abstract}

\section{Keywords}

Polypropylene fiber reinforced concrete; Instrumented drop weight test; Impact behavior; Impact resistance; Energy absorption

Received: 21 October 2021; Accepted: 16 December 2021

ISSN: 2630-5763 (online) C 2021 Golden Light Publishing All rights reserved.

\section{Introduction}

As a building material, concrete is widely used in civil engineering as it allows economical, safe, and aesthetic designs. It is exposed to many different types of loads throughout its life. Impact effect is in question for some structures and structural members. The crash of sea vehicles against port structures at low speeds, the fall of weight on the floor in industrial buildings, the collision of the weights carried by cranes against the columns, and the vehicles crash against the columns in car parks may be considered impact effects. Concretes weak properties, such as low tensile strength and energy- absorbing capacity under such impact effects, are trying to be improved over time.

Concrete containing randomly oriented discontinuous fibers is called Fiber Reinforced Concrete (FRC). Randomly oriented fibers can effectively resist crack propagation in the cement matrix and improve the post-cracking ductility of concrete under both static and impact loads [1]. The fibers added to the concrete mixture for purposes such as improving the tensile strength, increasing the resistance of the concrete against dynamic loads, preventing the fragmentation or dispersion of

\footnotetext{
Corresponding author

Email: ismailunsl@gmail.com
} 
the material, and limiting the growth of the cracks have various chemical and geometrical properties.

The fibers added to the concrete mixture can be steel, polypropylene, polyethylene, polyester, carbon, glass, etc. Although many studies have been done so far, fiber-reinforced concrete still attracts researchers' great interest. Yoo and Banthia [1] have included an extensive literature review on the impact behavior of fiber-reinforced concrete in their study.

Al-Masoodi et al. [2] used steel and polypropylene fibers in various shapes, sizes, and lengths in their study to determine the compressive, tensile, and flexural strengths of fiber-reinforced concretes under static and dynamic effects. They used the Split-Hopkinson pressure bar test setup to examine the impact behavior of fiber-reinforced concrete samples. In their investigations on polypropylene fiber reinforced concrete, they observed that as the amount of polypropylene fiber increases, the compressive strength and toughness increase compared to plain concrete, and the behavior of FRC improves under dynamic effects. These results appear to agree with the findings previously reported by Banthia et al. [3]. It has been observed that polypropylene fibers improve concrete's mechanical properties under impact than the concrete under static load. In addition, crimped polypropylene fibers exhibited a much superior impact behavior than straight and long fibers by improving energy absorption capacity. Moreover, long fibers exhibited better impact behavior compared to short fibers.

Almusallam et al. [4,5] studied the impact behavior of hybrid fiber reinforced normal strength, and high strength concretes using a combination of steel and plastic fibers. The study stated that steel fibers were more effective on impact resistance than polypropylene fibers, while hybrid fiber reinforced concrete was more effective than the other two, and the steel/polypropylene fiber ratio was suggested as 2:1.

Studies also examine the interaction of the substitute materials (in the concrete mixture) with polypropylene fibers. Alhozaimy et al. [6] observed that using substitute materials such as fly ash, silica fume, and slag in polypropylene fiber-reinforced concrete significantly improved the impact behavior of PFRC. They attributed this improvement to the fact that the pozzolanic activity developed in concrete increased the adherence between polypropylene fibers and cement paste.

Caf [7] added steel fiber $(0.5 \%, 1 \%, 1.5 \%, 2 \%$ by volume) and polypropylene fiber ( $300 \mathrm{~g}, 600 \mathrm{~g}, 900$ $\mathrm{g}, 1200 \mathrm{~g}$ per cubic meter) in different proportions to concrete mixture. It has been concluded that adding steel fibers to the concrete mixture up to $1 \%$ by volume contributes to the concrete compressive strength. For the tensile strength, a significant increase was observed with the addition of $2 \%$ steel fiber. The addition of steel fiber provided a considerable benefit to concrete impact behavior. The study also stated that adding more than a certain amount of fiber reduces the workability of concrete.

Korkut et al. [8] investigated the mechanical properties of steel and synthetic fiber-reinforced concrete and performed compressive and splitting tensile stress tests. The study concluded that the highest strength increase was in the $60 \mathrm{~mm}$ macro fiber-concrete mixture. According to the test results, although the increased strength was more elevated in concretes with steel fiber additives, synthetic fibers also contributed significantly to the concrete.

Şahin et al. [9] used M12 monofilament type polypropylene fiber and prepared two different groups of PFRC samples. The first group included the ratios of $0.2 \%, 0.4 \%, 0.6 \%, 0.8 \%, 1.0 \%$ for beam $(160 \times 160 \times 40 \mathrm{~mm})$ and cube $(40 \times 40 \times 40 \mathrm{~mm})$ samples and the second group included the ratios of $0.25 \%, 0.50 \%, 0.75 \%$ for beam $(100 \times 100 \times 500$ $\mathrm{mm})$ and cube $(100 \times 100 \times 100 \mathrm{~mm})$ samples. The mechanical properties of concrete, such as compressive, flexural, and impact strength, shrinkage, and microstructures, were examined in the study. A decrease in compressive strength was observed in response to increasing fiber content for all samples. The flexural strength of the samples in the first group was increased with increasing fiber ratio up to $0.6 \%$ and was decreased for higher fiber ratios beyond $0.6 \%$. Polypropylene fiber addition 
had a slightly improving effect on the flexural strength of the samples in the second group. An improvement in impact energy was observed for all the samples.

Polypropylene fiber-reinforced concrete has been the subject of various studies in the literature. However, studies including instrumented dropweight tests on PLTB beams are limited. The present study investigates polypropylene fiberreinforced concrete under static and dynamic loads. Static compression tests, three-point bending tests, and impact tests were performed on beam samples (with the dimension of $100 \times 100 \times 500 \mathrm{~mm}$ ). Static compression and impact tests were performed on cube samples (with the size of $100 \mathrm{~mm}$ ). PFRC mixtures were prepared by adding polypropylene fiber to the concrete mix in proportions of $0.22 \%$ (2 $\left.\mathrm{kg} / \mathrm{m}^{3}\right), 0.44 \%\left(4 \mathrm{~kg} / \mathrm{m}^{3}\right)$, and $0.66 \%\left(6 \mathrm{~kg} / \mathrm{m}^{3}\right)$ by volume.

\section{Material and method}

$350 \mathrm{~kg}$ of a cement dosage and 0.55 of watercement ratio were considered for concrete mixtures. Concrete mixtures include super-plasticizer with a proportion of $0.4 \%$ of the cement. Cement, water, aggregate, and plasticizer ratios are standard and the same for all the mixtures in the study. Table 1 shows the components of concrete mixtures per cubic meter.

The polypropylene fiber is a $60 \mathrm{~mm}$ long polypropylene fiber supplied by Atlas company, and its mechanical properties and the image are presented in Table 2 and Fig. 1, respectively.

Table 1. Concrete mix design (per cubic meter)

\begin{tabular}{lc}
\hline Material & Amount $(\mathrm{kg})$ \\
\hline Cement & 350 \\
Water & 192.5 \\
Fine aggregate & 747.27 \\
Medium aggregate & 538.12 \\
Coarse aggregate & 539.48 \\
Superplasticizer & 1.4 \\
\hline
\end{tabular}

Table 2. Mechanical and geometric properties of polypropylene fiber

\begin{tabular}{lc}
\hline Properties & Value \\
\hline Tensile strength (MPa) & $550-750$ \\
Length (mm) & 60 \\
Specific gravity g/cm ${ }^{3}$ & 0.91 \\
Fiber amount, Piece/kg & 200.000 \\
Modulus of elasticity (MPa) & $6,900-9,100$ \\
\hline
\end{tabular}

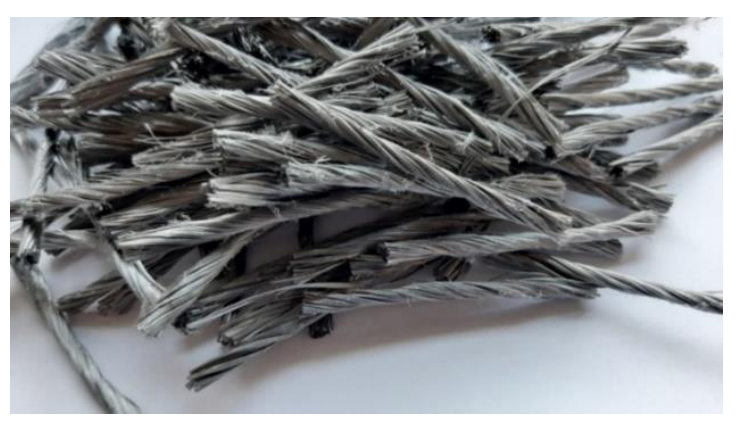

Fig.1. Image of polypropylene fiber

Polypropylene fiber was added to the prepared concrete mixtures in three proportions $(0.22 \%$, $0.44 \%$, and $0.66 \%$ by volume). A total of 4 different concrete mixes were prepared together with the control mix that did not contain fiber. Beam samples (with the dimension of $100 \times 100 \times 500 \mathrm{~mm}$ ) and cube samples (with the size of $100 \mathrm{~mm}$ ) were prepared according to TS EN 12390-1 [10]. A total of 48 specimens (three representative cube and beam specimens for each of four mixes) were prepared for static compression tests, three-point bending tests, and impact tests.

Pendulum, Izod and Charpy, and Drop-weight tests are in the group of low-velocity impact tests. Split-Hopkinson pressure bar test and compressed air impact tests are high-speed impact tests. A dropweight impact test is performed by dropping a certain weight on the sample from a certain height. There are two types of drop-weight tests, with and without instruments. The instrumented drop-weight impact test method is used to determine the dynamic properties of the material. Unlike other methods, using different weights and adjusting different heights can provide the desired energy and velocity. Moreover, the instrumented drop-weight 
impact test system can perform the sample's sticking, puncture, and repeated impact tests.

In this study, instrumented drop-weight impact tests were carried out according to ACI 544.2R [11] using an Instron Ceast 9350 device (Fig. 2).

A crack detection microscope from the supplier of ELE International was used to measure crack width in the middle of beams under impact (Fig. 3).
Beam samples were subjected to a line distributed impact load at the midpoint by the free fall of a $6,235 \mathrm{~kg}$ weight from a height of $736 \mathrm{~mm}$. $45 \mathrm{~J}$ of energy was applied to the beam sample accordingly. Cube samples were subjected to a point impact load by free fall of a $25,5 \mathrm{~kg}$ hemispherical weight from a height of $800 \mathrm{~mm}$, and $200 \mathrm{~J}$ of energy was applied accordingly.

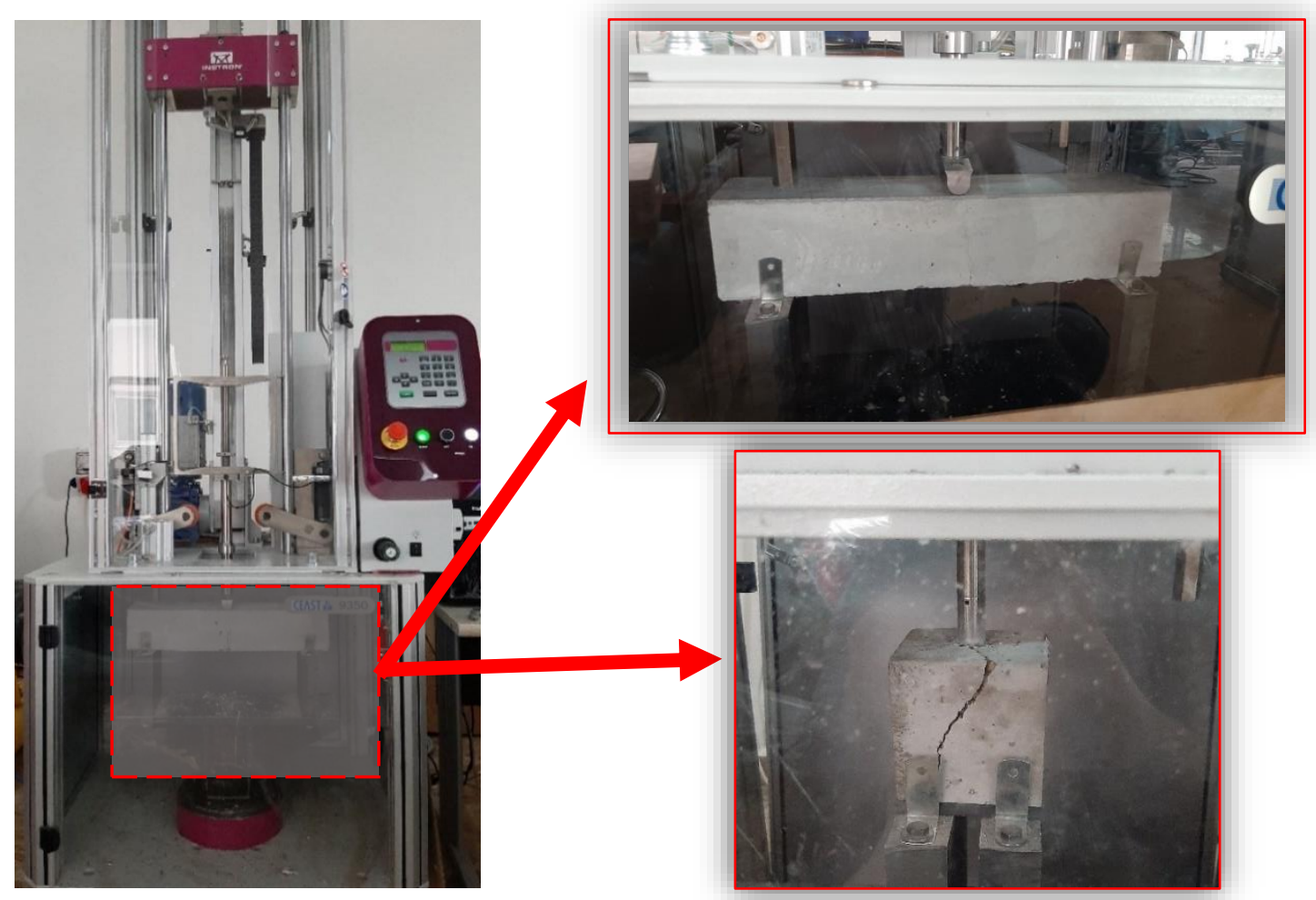

Fig.2. Instron Ceast 9350, the instrumented drop-weight test machine

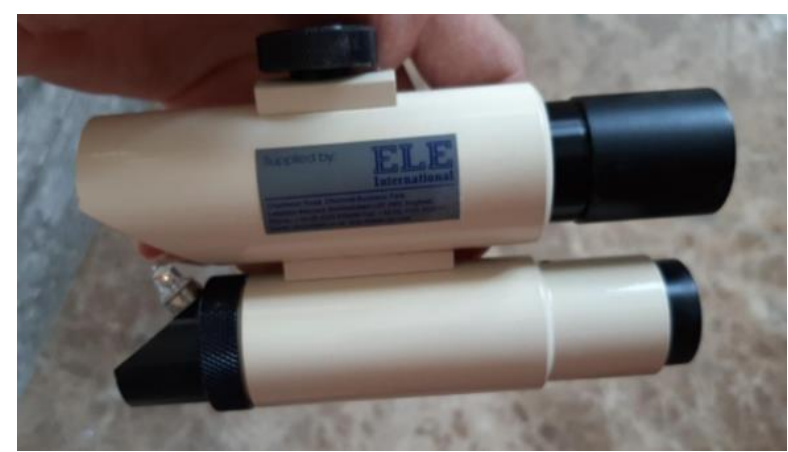

Fig.3. Crack detection microscope 


\section{Results and discussion}

Static compression and flexural tests were carried out on both control and polypropylene fiberreinforced concrete cube and beam samples, respectively. Then, impact tests were conducted on beam (with line distributed impact load) and cube samples (with point impact load).

The results of the static tests performed according to TS EN 12390-5 [12] were illustrated graphically in Fig. 4 and Fig. 5.

It is observed in Fig. 4 that the compressive strength of the concrete slightly increased with the addition of polypropylene fiber to the concrete mix. The highest strengths were obtained with a polypropylene fiber ratio of $0.22 \%$. The compressive strength slightly decreased for higher ratios beyond $0.22 \%$. The standard deviation was calculated as 4.94, 4.02, 6.02, and 1.90 for fiber ratios of 0, 0.22, 0.44, and 0.66, respectively in Fig. 4. The standard errors are shown in the figure. The standard deviation was $0.68,0.04,0.07$, and 0.39 for flexural strength in Fig. 5. Similarly, the addition of polypropylene fiber to the concrete mixture improved flexural tensile strength (Fig.5). Banthia and Trottier [13] stated in their study that the bridging effect created by the randomly dispersed steel fibers in the matrix after the first crack delayed the propagation of cracks in steel fiber reinforced concrete. The polypropylene fibers in the present study may create a similar effect and slightly increase the flexural tensile strength.

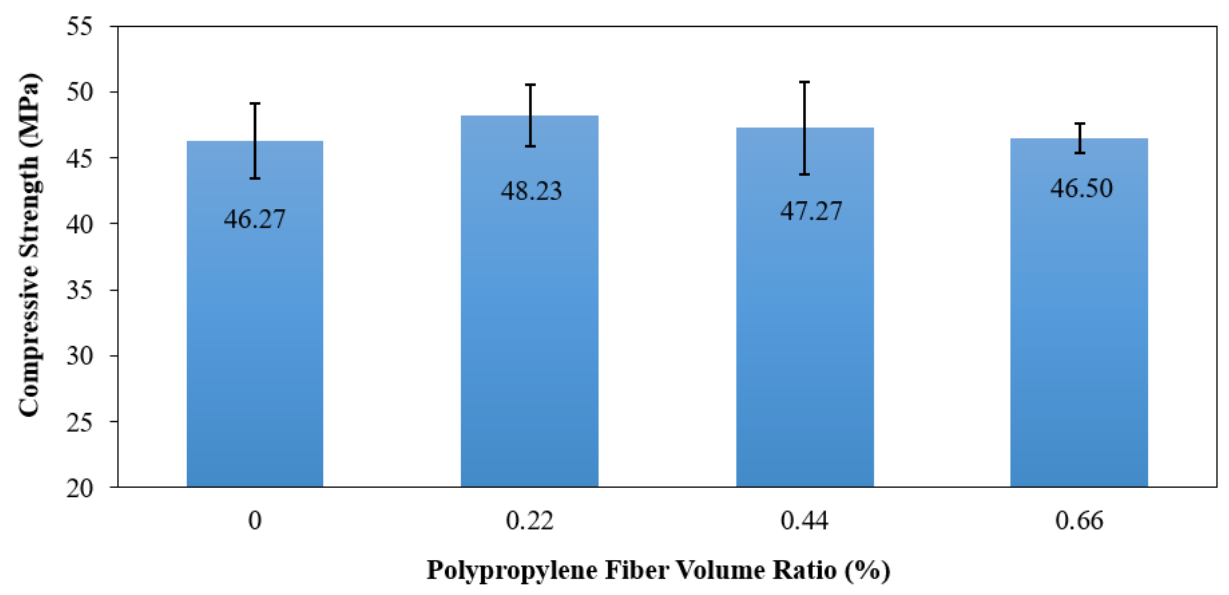

Fig.4. Compressive strength of samples

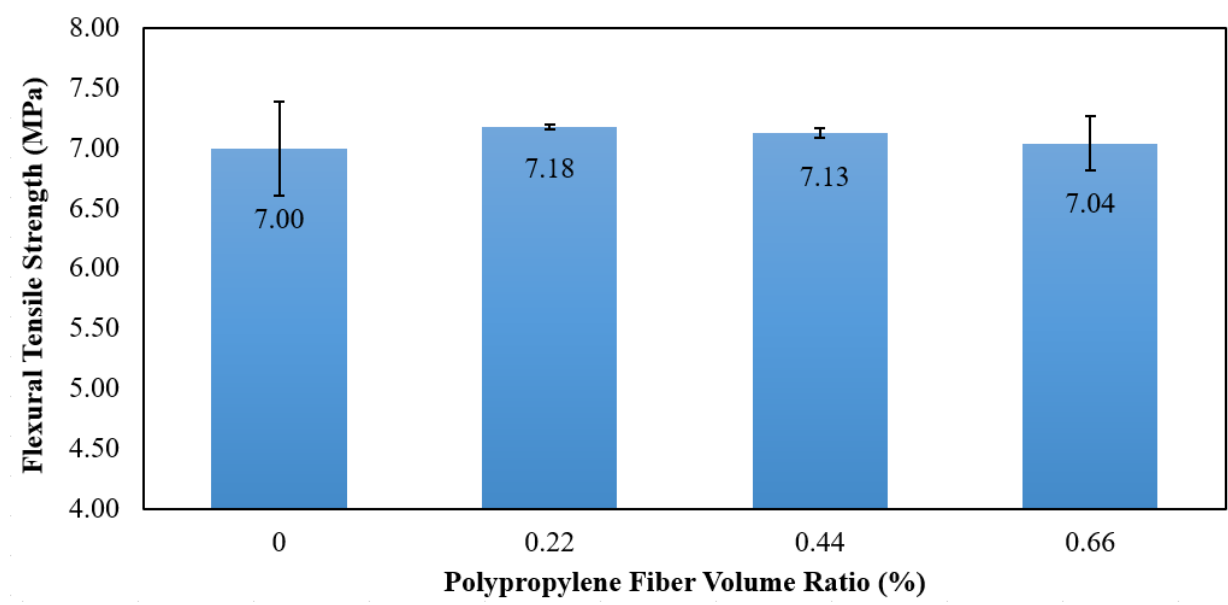

Fig.5. Flexural tensile strength of samples 
PFRC beam samples with a polypropylene fiber ratio of $0.22 \%$ exhibited better performance than the samples with a fiber ratio of $0.44 \%$ and $0.66 \%$, under static loading. These findings are consistent with the literature $[7,9,14]$. Increasing polypropylene in the concrete mix may cause lower workability, leading to less compacting and a decrease in strength. Furthermore, it was reported in the literature that polypropylene fibers' lower density, lower compression strength, and low bond strength might also decrease compressive strength $[9,15]$. However, some studies indicate that the compressive and flexural strengths of PFRC samples increased as the fiber ratio increased $[2,16]$.

Polypropylene fibers have less influence on the static properties of plain concrete, whereas they significantly improve the dynamic compressive properties [1]. Fig. 6 shows load history graphics of beam samples under impact. Peak loads were obtained as 34.7, 37.7, 38.9, and $39.0 \mathrm{kN}$ for control and PFRC beam samples with the fiber ratio of 0 , $0.22,0.44$, and 0.66 , respectively. The addition of $0.66 \%$ polypropylene fibers into the concrete mixture led to a $12.6 .0 \%$ higher peak load than control concrete under impact. The lowest peak load value is for the control sample, and the peak load increases with the increment of the polypropylene fiber ratio. This character of the curves in Fig. 6 also appeared in the test data on steel fiber reinforced concrete previously reported by Yoo et al. [17]. As stated in that study, matrix softening and fiber bridging effect dominates bending behavior when the first crack occurs. The peak load represents the initial cracking load in the FRC beams. Immediately after the first crack appears, the impact load is significantly reduced, and if there is no fiber in the matrix, the impact load progresses to zero. However, if fibers are present in the matrix, the impact load gradually decreases due to the fiber bridging effect [17]. It was also observed in Fig. 6 that the tendency of curves to approach zero decreases as the polypropylene fiber ratio increases.

The energy-time relationship of beam samples under impact can be seen in Fig. 7. The energy was obtained as $8 \mathrm{~J}$ for control samples, and the maximum energy was obtained at $17 \mathrm{~J}$ for PFRC beam samples with a fiber ratio of $\% 0.66$. Therefore, adding $\% 0.66$ polypropylene fibers into the concrete mixture led to a $\% 120.9$ increase in energy than control concrete under impact. The increase of polypropylene fibers ratio in concrete mix resulted in better absorption of impact energy. Suaris and Shah [18] also reported better energy absorption in steel fiber reinforced beams than the plain concrete beams under impact. The character of the curves in Fig. 7 shows that the rate of increase in the energy over time is higher as the polypropylene fiber ratio increases.

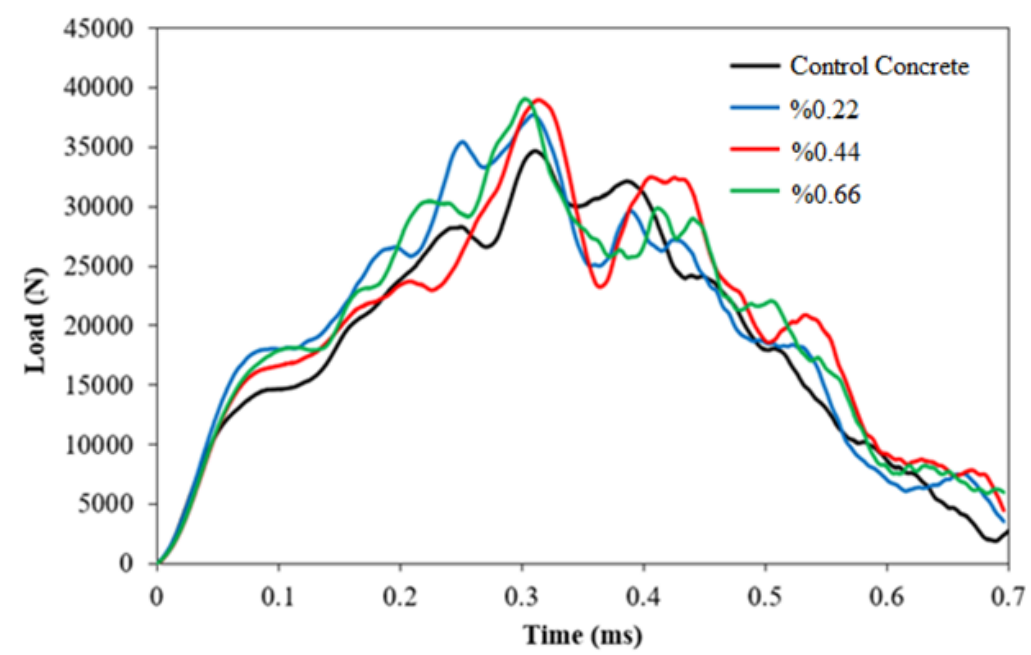

Fig.6. Load history of beam samples under impact 


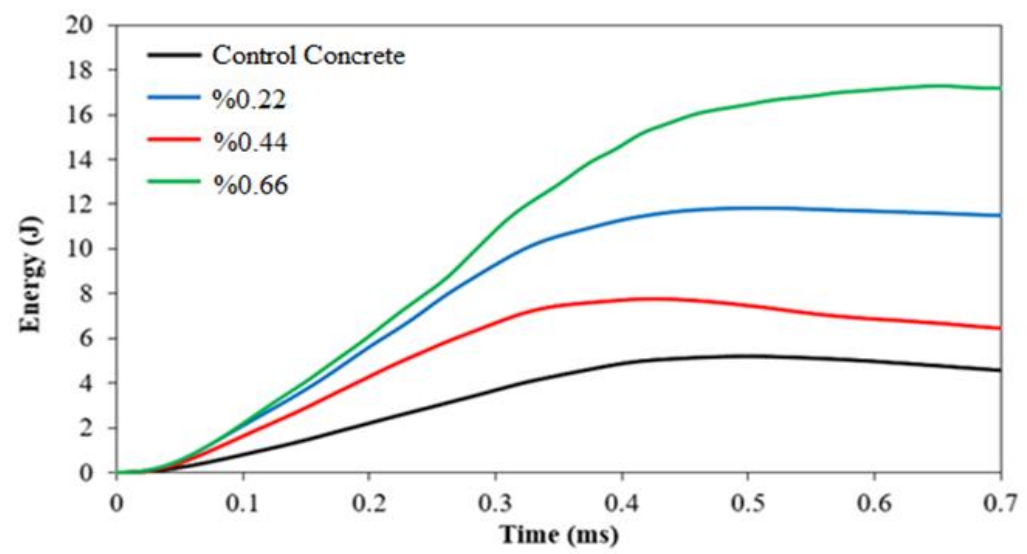

Fig.7. Energy history of beam samples under impact

The samples with the highest rate of increase are the samples with a polypropylene fiber ratio of $\% 0.66$, and the samples with the lowest rate are the control samples.

The image of the failure of the samples under impact can be seen in Fig. 8. The control samples were separated into two parts from the contact line under the impact, unlike the polypropylene fiberreinforced beams with a fiber ratio of $0.44 \%$ and $0.66 \%$. The initial cracks of PFRC occurred on the opposite surface of the impact and propagated towards the contact surface, but the crack width remained restricted. Failure mode and the crack width of beams under impact can be seen in Fig. 8 and Fig. 9, respectively. The value of crack widths given in Fig. 9 shows the average value of three samples for each mix.

Although the PFRC beams with a fiber ratio of $0.22 \%$ split into two under the impact, it is seen that the cracks formed in the beams are restricted by increasing the polypropylene fiber ratio. PFRC samples exhibit significantly improved impact behavior compared to plain concrete. It is seen that this behavior is in agreement with the results in the study of Yoo and Banthia [1].

Fig. 10 shows load history graphics of cube samples under impact. Peak loads were obtained as 36.4, 40.0, 41.1, and $39.5 \mathrm{kN}$ for control and PFRC beam samples with the fiber ratio of $0,0.22,0.44$, and 0.66 , respectively. The addition of $0.44 \%$ polypropylene fibers into the concrete mixture led to a $13.1 \%$ higher peak load than control concrete under impact

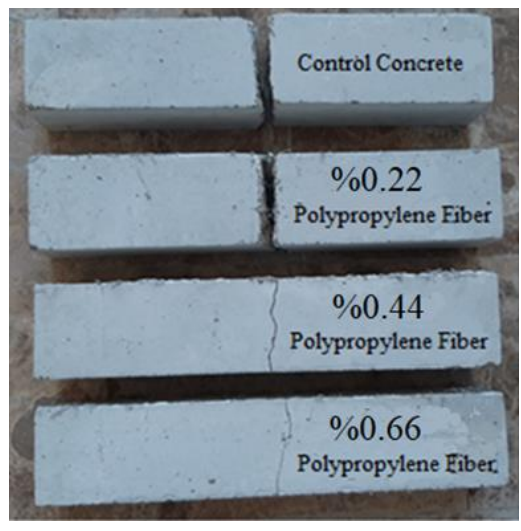

Fig.8. The failure mechanism of beams under impact

Like the beam samples, the lowest peak load value is for the control sample, and the peak load increases with the increment of the polypropylene fiber ratio. The decrease in the tendency of curves to approach zero is more apparent for cube samples than the beams.

The energy-time relationship of cube samples under impact can be seen in Fig. 11. The energy was obtained as $137.6 \mathrm{~J}$ for control samples, and 7.2\%, $6.6 \%$, and $5.4 \%$ increase were observed for fiber ratio of $0.22 \%, 0.44 \%$, and $0.66 \%$, respectively. The increase of polypropylene fibers ratio in concrete mix resulted in better absorption of impact energy, similarly to beam samples. The amount of absorbed energy for all PFRC mixes is almost equal, while the lowest is for the control samples.

The failure mode of cube samples under impact can be seen in Fig. 12. The control samples were separated into two parts, unlike the polypropylene fiber-reinforced beams. 


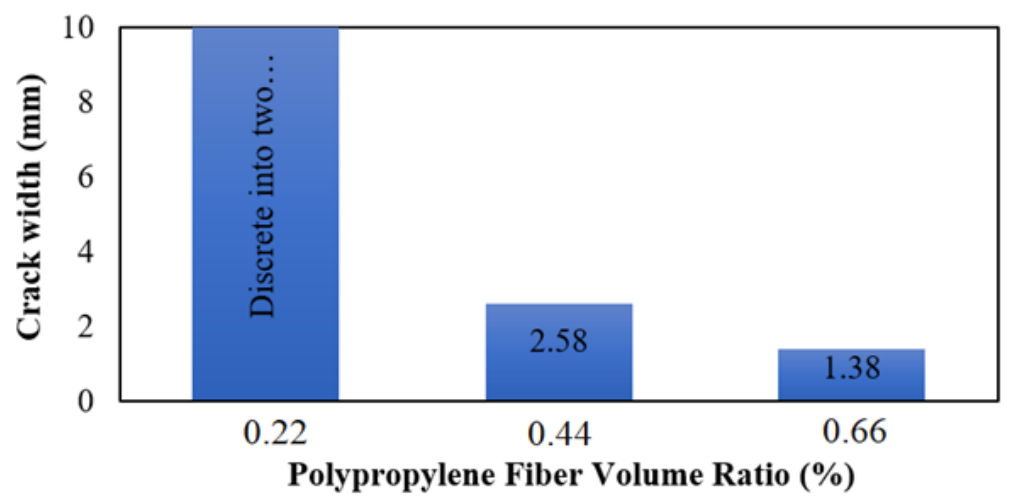

Fig. 9. Crack width of beams under impact



Fig.10. Load history of cube samples under impact

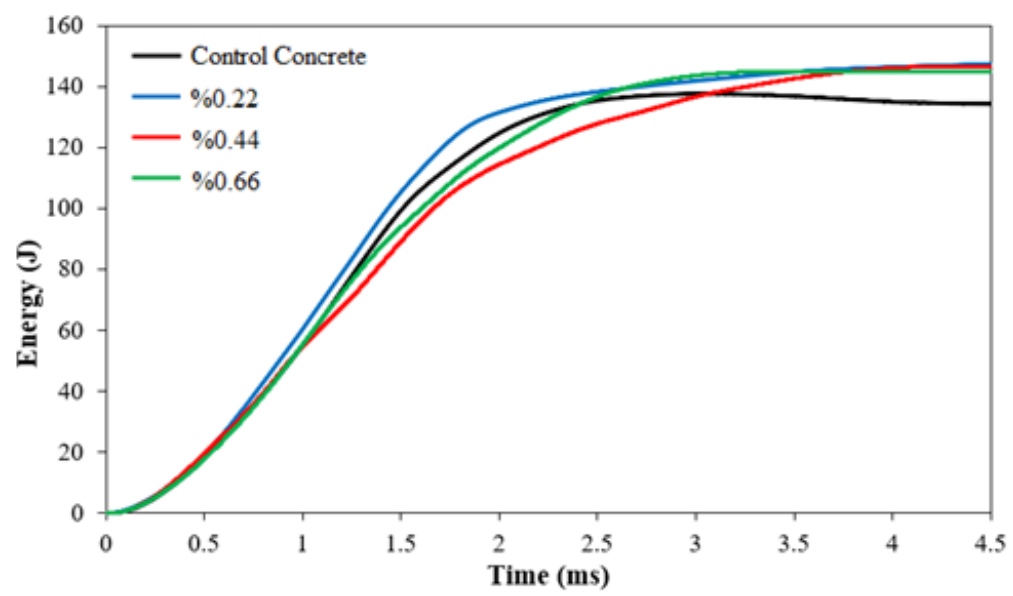

Fig. 11. Energy history of cube samples under impact 


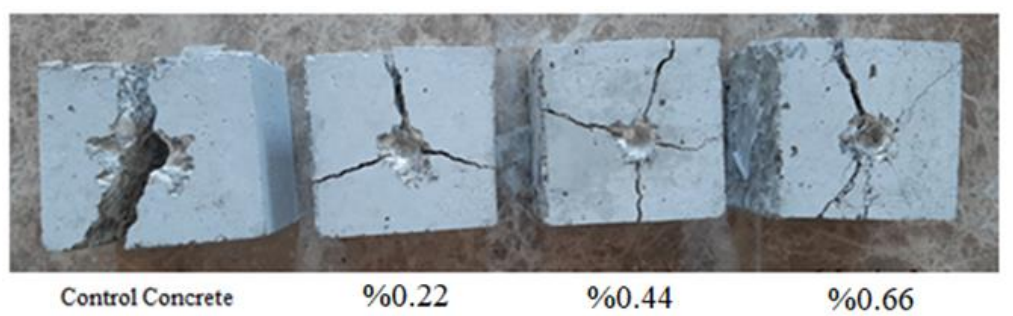

Fig.12. The failure mechanism of cube samples under impact

\section{Conclusions}

The impact behavior of polypropylene fiberreinforced concrete cube and beam samples and the effect of fiber ratio on the behavior were investigated in this study. Fiber-reinforced concrete mixtures with fiber ratios of $0.22 \%, 0.66 \%$, and $\% 0.66$ by volume were fabricated together with the control mixture. In addition to static tests, the instrumented drop-weight impact tests were also carried out on the samples. Crack width measurements were recorded for cracks formed in the middle of the beam under impact effect. The following findings were obtained from the experiments in the study, which were carried out to reveal the behavior that may occur in structural elements exposed to low-speed impact effects.

The fracture of control beam and cube samples occurred suddenly, and the samples were separated into two parts under the impact, while the polypropylene fiber in PFRC prevents the sudden failure of concrete. This contribution was developed depending on the polypropylene fiber ratio in the mixture. However, the PFRC beams with a fiber ratio of $0.22 \%$ split into two under the impact, the polypropylene fiber ratio of $0.44 \%$ and $0.66 \%$ prevented fragmentation and restricted cracks in the beams. Line distributed impact load caused a visible crack attempting to split the beams into two, and the PFRC cubes tended to separate into three or four pieces with multiple cracks under point impact load, but no separation occurred in any of the PFRC cubes. The improvement in the absorbed energy was more pronounced for beams rather than cubes.

The control samples had the lowest peak load value on load history graphics of cube and beam samples. With the polypropylene fiber ratio increment in the mixture, the peak load increased, and the tendency of curves to approach zero after peak load decreased due to the fiber bridging effect. It was observed that the fracture properties of polypropylene fiber reinforced concrete for both cube and beam samples were better than the control samples under impact. The crack width in the beams under the impact decreased with the increase in polypropylene fiber ratio. The cube and beam concrete samples reinforced with polypropylene fibers absorbed the impact energy better than the control samples.

The highest strength was obtained in the samples with the polypropylene fiber ratio of $0.22 \%$ in the compression and three-point bending static tests. As a result of impact tests, samples with a fiber ratio of $0.66 \%$ showed the best performance. Considering the polypropylene fiber ratios used in the tests performed in this study, $0.22 \%$ fiber ratio stands out for members subject to static loads and $0.66 \%$ fiber ratio for members that may be subject to impact load.

\section{Declaration of conflicting interests}

The author(s) declared no potential conflicts of interest with respect to the research, authorship, and/or publication of this article.

\section{References}

[1] Yoo DY, Banthia N (2019) Impact resistance of fiber-reinforced concrete $-\mathrm{A}$ review. Cement and Concrete Composites 104:103389.

[2] Al-Masoodi AHH, Kawan A, Kasmuri M, Hamid R, Khan MNN (2016) Static and dynamic properties of concrete with different types and shapes of fibrous reinforcement. Constr. Build. Mater. 104:247-262. 
[3] Banthia N, Gupta P, Yan C (1999) Impact resistance of fiber reinforced wet-mix shotcrete Part I: beam tests. Mater. Struct. 32(8):563-570

[4] Almusallam TH, Siddiqui NA, Iqbal RA, Abbas H (2013) Response of hybrid-fiber reinforced concrete slabs to hard projectile impact. Int. J. Impact Eng. 58:17-30.

[5] Almusallam TH, Abadel AA, Al-Salloum YA, Siddiqui NA, Abbas H (2015) Effectiveness of hybrid-fibers in improving the impact resistance of RC slabs. Int. J. Impact Eng. 81:61-73.

[6] Alhozaimy AM, Soroushian P, Mirza F (1996) Mechanical properties of polypropylene fiber reinforced concrete and the effects of pozzolanic materials. Cement Concr. Compos. 18(2):85-92

[7] Caf M (2012) Polipropilen ve Çelik Lifli Betonların Darbe Dayanımı. MSc Thesis, Atatürk University (in Turkish).

[8] Korkut F, Türkmenoğlu ZF, Taymuş RB, Güler S (2017) Çelik ve sentetik liflerin kendiliğinden yerleşen beton taze ve meknik özellikleri üzürine etkisi. Ömer Halisdemir Üniversitesi Mühendislik Bilimleri Dergisi 6(2):560-570 (in Turkish).

[9] Şahin M, Karagöz I, Öksüz M, Yazıcıŏlu S (2021) Properties of concrete reinforced with M12 monofilament type polypropylene fiber. El-Cezerî Journal of Science and Engineering 8(1):481-494.

[10] TS EN 12390-1 (2014) Beton-Sertleşmiş Beton Deneyleri-Bölüm 1: Deney Numunesi ve Kalıplarının Boyut ve Diğer Özellikleri, Ankara.
[11] ACI 544.2R (2009) Measurement of Properties of Fiber Reinforced Concrete, USA

[12] TS EN 12390-5 (2010) Beton-Sertleşmiş Beton Deneyleri-Bölüm 5: Deney Numunelerinde Eğilmede Çekme Dayanımının Tayini, Ankara.

[13] Banthia N, Trottier JF (1995) Concrete reinforced with deformed steel fibers, Part II: Toughness characterization. ACI Mater. J. 92(2):146-154.

[14] Mohamed RAS (2006) Effect of polypropylene fibers on the mechanical properties of normal concrete. Journal of Engineering Sciences-Assiut University 34(4):1049-1059.

[15] Richardson AE (2006) Compressive strength of concrete with polypropylene fiber additions, Structural Survey 24(2):138-153.

[16] Hsie M, Tu C, Song PS (2008) Mechanical properties of polypropylene hybrid fiber-reinforced concrete. Materials Science and Engineering A 494:153-157.

[17] Yoo D-Y, Gohil U, Gries T, Yoon YS (2015) Comparative low-velocity impact response of textile-reinforced concrete and steel-fiberreinforced concrete beams. Journal of Composite Materials 50(17):2421-2431.

[18] Suaris W, Shah SP (1982) Strain-rate effects in fiber-reinforced concrete subjected to impact and impulsive loading. Compos 13(2):153-159. 